BULLETIN Bulletin hispanique

HISPANIQUE Université Michel de Montaigne Bordeaux

$112-2 \mid 2010$

Varia

\title{
Fernando vs. Gabo
}

Jacques Joset

\section{(Q) OpenEdition \\ Journals}

Edición electrónica

URL: http://journals.openedition.org/bulletinhispanique/1277

DOI: 10.4000/bulletinhispanique.1277

ISSN: $1775-3821$

\section{Editor}

Presses universitaires de Bordeaux

\section{Edición impresa}

Fecha de publicación: 31 diciembre 2010

Paginación: 821-831

ISBN: 978-2-86781-709-0

ISSN: 0007-4640

\section{Referencia electrónica}

Jacques Joset, « Fernando vs. Gabo », Bulletin hispanique [En línea], 112-2 | 2010, Publicado el 05 enero 2014, consultado el 19 abril 2019. URL : http://journals.openedition.org/bulletinhispanique/1277 ;

DOI : 10.4000/bulletinhispanique.1277 


\title{
Fernando vs. Gabo
}

\author{
JACQues Joset \\ Université de Liège - Belgique
}

Fernando Vallejo n'a cessé de multiplier des attaques contre les opinions politiques et l'écriture de García Márquez. On tente de retracer les étapes de cette démarche aggressive et unilatérale de l'auteur de La Virgen de los sicarios à l'égard de son compatriote, d'en démonter le mécanisme et d'en cerner les raisons.

No ha dejado Fernando Vallejo de atacar tanto las posturas políticas como la escritura de García Márquez. Se intenta seguir el desarrollo cronológico de esa actitud agresiva y unilateral del autor de La Virgen de los sicarios con respecto a su compatriota así como desarmar el mecanismo y la motivación de la misma.

Fernando Vallejo did not stop attacking not only Garcia Márquez' political positions, but also his writing. This study attempts to follow the chronological development of the aggressive and unilateral attitude of the author of La Virgen de los sicarios towards his compatriot, as well as to dismantle the mechanism and motivation of the same.

Mots-clés : Fernando Vallejo - Gabriel García Márquez - Polémique.

T A historia tiene principios más bien halagadores. En la introducción 1 de Logoi. Una gramática del lenguaje literario (1983), Fernando Vallejo cita una frase de Cien años de soledad (1967) como ejemplo de «una fórmula literaria que permite distribuir una enumeración de sustantivos, adjetivos, verbos o complementos en varios grupos de dos términos, más o menos

Bulletin Hispanique, Tome 112, n 2 - décembre 2010 - p. 821 à 831. 
opuestos, unidos por la conjunción ${ }^{1} »$. La frase en cuestión no opone los términos dos a dos sino que distribuye «hortalizas» en grupos de dos voces unidos por $y$ : «Fue esa la época en que adquirió el hábito de hablar a solas, paseándose por la casa sin hacer caso de nadie, mientras Úrsula y los niños se partían el espinazo en la huerta cuidando el plátano $y$ la malanga, la yuca $y$ el ñame, la ahuyama $y$ la berenjena ${ }^{2}$.» Si bien, comenta el gramático del lenguaje literario, la lógica obligaría a yuxtaponer los términos de la enumeración con excepción de los dos últimos trabados por una $y$ única, «estamos ante un esquema literario preexistente a los escritores de las diversas épocas e idiomas, por el cual se distribuyen los términos de una enumeración en grupos de dos por lo general, opuestos o no, según un ritmo y un equilibrio eufónico. Y la eufonía, por sobre el sentido mismo, es la gran razón de la literatura». (Logoi., ibidem)

El elogio no podía ser más encomiástico: en la época de redacción de Logoi, Fernando Vallejo otorgaba a Gabo el reconocimiento debido al escritor que pone por encima de todo el cuidado estilístico. El músico que era (y sigue siendo) no podía dejar de admirar la eufonía fraseológica de su compatriota.

Veinte años después de la publicación de Logoi, otro es el cantar. Interrogado en el documental de Luis Ospina, La desazón suprema. Retrato incesante de Fernando Vallejo (2003) sobre lo que piensa de García Márquez como escritor, Vallejo contesta: «No es un escritor muy original. Es un escritor de camino trillado, recorrido. Y pienso que es un prosista regular. Su prosa no es rica ni sintácticamente ni lexicográficamente.» Así de tajante. ¿Qué ocurrió entre 1983 y 2003 para que la admiración sino por un estilo, al menos por un rasgo estilístico, se trocase en una condena general apenas matizada por la apreciación «regular» de la prosa del autor colombiano más celebrado del la segunda mitad del siglo XX?

Aunque no faltan datos sobre el distanciamiento de Vallejo con respecto a García Márquez en tanto escritor, me parece que un artículo publicado en el número de la revista El malpensante de noviembre-diciembre de 1998 titulado «Cursillo de orientación ideológica para García Márquez» marca un hito esencial en este proceso ${ }^{3}$. Este relato del primer viaje de Fernando

1. Fernando Vallejo, Logoi. Una gramática del lenguaje literario, México, Fondo de Cultura Económica, 1997 (1a reimpresión), p. 21.

2. Gabriel García Márquez, Cien años de soledad, ed. de Jacques Joset, Madrid, Cátedra, «Letras hispánicas», 215, 2007 (18 a ed.), p. 87. Lo subrayado es de Fernando Vallejo.

3. Fernando Vallejo, "Cursillo de orientación ideológica para García Márquez», in El Malpensante (Bogotá), núm. 13, noviembre-diciembre de 1998, pp. 44-67. Agradezco encarecidamente al editor de la revista, Camilo Jiménez, el envío de la versión electrónica de 
Vallejo a Cuba del que una versión con variantes pero sin pullas aparentes contra Gabo se publicó en Entre fantasmas (1993) ${ }^{4}$, empieza con una descripción más bien socarrona de las actitudes de García Márquez con los «grandes» de la política internacional hispánica de aquella época. Sus nombres vienen rebajados por diminutivos nada carińosos en este caso: Fidelito Castro, Felipito González, Cesarito Gaviria, Miguelito de la Madrid, Carlitos Andrés Pérez, Carlitos Salinas de G., Ernestico Samper. Aquí como en otros lugares, el autor de El río del tiempo rechaza radicalmente cualquier categoría de protagonismo. El anarquismo de que siempre hizo gala es tanto más implacable cuanto que los aduladores del poder, de todos los poderes, simbólico o político, son escritores. De ahí por ejemplo su inquina contra Octavio Paz, satirizado a lo largo y ancho de sus autoficciones. Una presa tan jugosa como García Márquez que nunca ocultó su fascinación por el poder y los pudientes no podía escapar a su mirada terrible y temiblemente aguda. Hablando de Cuba, por supuesto, Vallejo tiene en el punto de mira a Fidel Castro, injuriado junto con García Márquez en el ápice conclusivo del «Cursillo». Con Jesús, el «muchacho» con el que acaba de acostarse, se ríe «del tirano, y de sus putas barbas, y de su puta voz de energúmeno y de loco, y de todos los lambeculos aduladores suyos como vos» ${ }^{5}$.

Sin embargo la oposición ideológica no arrastra necesariamente una descalificación estética: uno puede muy bien no compartir y hasta luchar contra la ideología racista de Louis-Ferdinand Céline o las provocaciones antihumanistas del mismo Fernando Vallejo y reconocer en sus prosas dos monumentos insustituibles de la literatura del siglo XX. Por lo tanto para redondear su rechazo, Vallejo tendrá que acompañar el repudio ético-político de un argumento de técnica literaria.

Es así como matará de un tiro tanto la adulación de Gabo para los detentores de un poder político siempre sospechoso como el enfoque narrativo de sus novelas. Después de recordar que no había visto a García Márquez en el

este artículo que fue reseñado en la sección cultura de El tiempo del 26 de diciembre de 1998 bajo el título de «La patada del elefante».

4. Fernando Vallejo, Entre fantasmas, in El río del tiempo, Bogotá, Alfaguara, 2003 (1ª reimpresión de la $2^{\text {a }}$ ed.), pp. 649-650.

5. En la primera columna de opinión («Por el desafuero») que Vallejo publica en la revista SoHo, 58, 15 de diciembre de 2004, no desaprovecha el ataque virulento al Presidente Álvaro Uribe para declarar su desprecio a García Márquez, "primer lambeculos de tiranos y granujas con poder que hoy tiene América.» Supongo que cuando echa a Gabriel García Márquez "por la alcantarilla» (Letralia. Tierra de letras, VIII, ${ }^{\circ}$ 97, 4 de agosto de 2003, consultado el 07/02/2009 en el sitio www.letralia.com/texto/ letra097/text), Vallejo se refiere al adulador de los grandes no al escritor. 
entierro de Luis Donaldo Colosio, candidato asesinado aunque designado por Carlos Salinas para sucederle en la Presidencia de México, le suelta un discurso empapado en una ironía despiadada:

¿Pero por qué te estoy contando a vos esto, tu propia vida, que vos conocés tan bien? ¿Narrándole yo, un pobre autor de primera persona, a un narrador omnisciente de tercera persona su propia vida? ¿Eso no es el colmo de los colmos? No, Gabito: Es que yo soy biógrafo de vocación, escarbador de vidas ajenas ${ }^{6}$, y te vengo siguiendo la pista de periódico en periódico, de país en país y de foto en foto en el curso de todos estos largos años por devoción y admiración. Tu vida me la sé al dedillo, pero ay, desde fuera, no desde dentro porque no soy narrador de tercera persona y no leo, como vos, los pensamientos. Vos me llevás a mí en esto mucha ventaja desde que descubriste a Faulkner, la tercera persona, el hielo y el imán.

Sin sospechar en 1998 que Gabriel García Márquez iba a sacrificar la tercera persona por la primera en su autobiografía Vivir para contarla (2002), Vallejo terminaba el «Cursillo» con una frase que trababa íntimamente el uso de la omnisciencia narrativa y la represión política, la tercera persona y la intolerancia, con una alusión más que probable en forma de boomerang a la última novela publicada de Gabo en aquel entonces, Del amor y otros demonios (1994):

Ya no te cuento más, no tiene caso, vos sos novelista omnisciente y de la Seguridad del Estado y todo lo sabés y lo ves, como veía la Santa Inquisición a los amantes copulando per angostam viam en la cama: los veía la suso dicha en el lecho por un huequito.

Fernando y Jesús copulando per angostam viam vigilados por la Seguridad del Estado cubano con la complicidad de García Márquez se identifican con Cayetano Delaura y Sierva María perseguidos por la Santa Inquisición de la novela en tercera persona ideada por el mismo Gabo ${ }^{7}$.

6. Ya en 1998 Fernando Vallejo había publicado las biografías de Porfirio Barba Jacob (1991) y de José Asunción Silva (1995).

7. Invitado por un entrevistador a opinar sobre la posibilidad de renovación de las novelas en tercera persona, con una mención explícita de Cien años de soledad, Vallejo da una larga lista de autores de $3^{\text {a }}$ persona, omitiendo a García Márquez como si fuera mejor olvidarlo, y comenta: «El del novelista en tercera persona, omnisciente o no, es el camino más trillado de la literatura y no lleva a ninguna parte.» (Javier Fernández, «Fernando Vallejo: la voz del muerto", in Literate World, 3 de febrero de 2002 (consultado el 7 de febrero de 2009 en el sitio www.literateworld.com/spanish/2002/entrevistas/feb03/w01/entre.html.) 
Por otra parte es muy posible que al mofarse de la diplomacia secreta que García Márquez no ha dejado de aducir para justificar su amistad con Fidel Castro ${ }^{8}$, Fernando Vallejo le dé un zarpazo al autor de El general en su laberinto (1989) tildándole de "sueño bolivariano» cuando cualquier lector de sus autoficciones sabe que convierte a Bolívar «en un personaje fraudulento y ambicioso, incapaz de fundar algo sólido o duradero.» ${ }^{9} \mathrm{~A}$ la figura humanizada del Libertador agonizante de El general en su laberinto, el último párrafo de El fuego secreto había opuesto ya en 1986 la visión del incendio de su estatua en el parque de Medellín:

Lo último que vi fue el parque, y en el parque, en llamas, el Libertador, la estatua. Ardía el mármol, ardía el bronce, ardía el caballo, ardía el héroe. ¡Adiós granhijueputa! ${ }^{10}$

Otra indirecta de índole literaria es la reacción del narrador de la anécdota del "Cursillo" al ser apuntado por el fusil de un soldado cubano en el momento en que estaba besando a Jesús en los prados del Hotel Nacional de La Habana: «-¿Qué hacés, niño, con ese juguete? -le increpé-. Apuntá para otro lado, no se te vaya a soltar una bala y acabés de un solo tiro con la literatura colombiana.» Identificando la literatura colombiana en su sola persona, Vallejo ninguneaba a quien, en Cuba y en el mundo, era su representante por antonomasia todavía en 1998. Otro tanto hacía al contestar ocho años más tarde la pregunta de un servidor sobre el hecho de que ni Álvaro Mutis ni García Márquez parecían ser santos de su devoción:

8. Sobre el tema véase el libro de Ángel Esteban y Stéphanie Panichelli, Gabo y Fidel. El paisaje de una amistad, Madrid, Espasa, 2004.

9. Gonzalo Aguilar, "El color de la violencia», in Clarín.com. Suplemento Cultura y Nación, 18.01.2003 (sitio http://old.clarin.com/suplementos/cultura/2003/01/18/u-00201. htm consultado el 07/02/2009). Otra intertextualidad más hipotética podría relacionar irrisoriamente el diálogo del «Cursillo»: «-[...] Si no me acuesto contigo esta noche me puedo morir. -Yo también me puedo morir -me contestó.» y la historia de los amantes de $E l$ amor en los tiempos del cólera (1985) que tienen que llegar a la decrepitud, o sea poco antes de morir, para acostarse. Más improbable todavía es el milagro del detenimiento del tiempo por Fidel Castro («[...] el monstruo había detenido a Cuba en un instante exacto de la eternidad.» y el tiempo estancado del cuarto de Melquíades en Cien años de soledad, ed. cit., pp. 291-292. Pero ¿será casual la ausencia de cambios en este cuarto y en el del difunto padre de Vallejo? La comparación de los textos deja la cuestión abierta: «Nadie había vuelto a entrar al cuarto desde que sacaron el cadáver de Melquíades», «no había el menor rastro de polvo» (Cien años de soledad, ed. cit., p. 291) frente a "[....] todo estaba igual, tal y cual él lo había dejado. Como no fuera la eternidad con sus primeras capas de polvo, nadie en el tiempo transcurrido había tocado nada.» (El desbarrancadero, Madrid, Alfaguara, 2001, p. 148).

10. Fernando Vallejo, El río del tiempo, ed. cit., p. 324. 
A mí me interesan Mariano José de Larra, Azorín y Manuel Mujica Láinez por razones técnicas, por asuntos de oficio, por su prosa, porque fueron los más grandes prosistas de este idioma. Sólo que un buen prosista es una cosa y un gran escritor es otra. Cervantes es un prosista mediocre pero un gran escritor ${ }^{11}$.

De la comparación con el juicio tajante del documental de Luis Ospina ( Su prosa no es rica ni sintácticamente ni lexicográficamente.»), se podría deducir que como Cervantes, Gabo sería «un prosista mediocre («regular», dijo en 2003) pero un gran escritor». Sin embargo la manera de eludir despectivamente el nombre de su colega en la respuesta no deja lugar a dudas: a los ojos de Fernando Vallejo, Gabriel García Márquez tampoco es un "gran escritor»" 12 .

Un mes antes de la publicación del «Cursillo de orientación ideológica para García Márquez», Vallejo concluía su discurso de inauguración del Primer Congreso de Escritores Colombianos con una de sus acostumbradas declaraciones de amor-odio a su país y otra indirecta despectiva a la narrativa de Gabo:

[...] Colombia con sus ambiciones, con sus ilusiones, con sus sueños, con sus locuras, con sus desmesuras me encendió el alma y me empujó a escribir. Ella prendió en mí la chispa, y cuando me fui, la chispa se vino conmigo encendida y me ha acompańado a todas partes, adonde he ido. Por eso no necesito inventar pueblos ficticios, y así pongo siempre en todo lo que escribo, siempre, siempre, siempre: «Bogotá», «Colombia», «Medellín» ${ }^{13}$.

11. Jacques Joset, «Entrevista a Fernando Vallejo», in Revista Iberoamericana, LXXII, 2006, pp. 653-655 (cita de las pp. 654-655).

12. Un incidente "extraliterario" no hizo probablemente nada para apaciguar les relaciones entre Vallejo, Mutis y García Márquez. A raíz de la ley de extranjería promulgada por el gobierno del Partido Popular que exigía el visado a los ciudadanos colombianos para entrar a España, en marzo de 2001 Vallejo firmó una carta al presidente José María Aznar, «con otros colombianos célebres, como García Márquez o Álvaro Mutis, para anunciar que no volvería a este país [España] a no ser que estas puertas se abrieran a los colombianos, y es el único que no ha ido en contra de su promesa.» (Juan Cruz, «Fernando Vallejo. Un heterodoxo extraordinario", in El País Semanal, n ${ }^{\circ} 1151,18$ de junio de 2006, pp. 12-20; cita de la p. 14).

13. Fernando Vallego, «El monstruo bicéfalo», in Revista Número, 20, 1998. Artículo consultado el 7 de febrero de 2009 en el sitio http://revistanumero.com/web/ index. php?catid $=48$. 
O sea nunca «Macondo, Macondo, Macondo». Como si dijera «mi realismo no soporta adjetivación alguna ni mucho menos la de mágico». O en términos de la periodista Laura Durango en su reseña de La rambla paralela (2002): «Nada que ver con las maravillas mágicas de su paisano Gabriel García Márquez, a quien Vallejo confiesa no aguantar» ${ }^{14}$ o de quien había preferido no opinar en julio de 1998 delante del corresponsal de El tiempo, Juan Carlos Iragorri, ya que del escritor de Aracatacá, dijo, «no puedo hablar bien» ${ }^{15}$. Pocos meses más tarde Vallejo iba a dejar de tener estos escrúpulos...

Como siempre en parecidas circunstancias, no faltaron periodistas y colegas para inmiscuirse en el debate. Así Gustavo Álvarez Gardeazábal declaraba con oportunidad de la desnaturalización de Vallejo como colombiano en 2007: "Hace rato que le han debido dar a Vallejo el premio Nobel, pues es el mejor escritor del país. Es superior a García Márquez.» Y sobre este tema el periodista de SoHo Luis Fernando Afanador ya había opinado lo mismo en artículos de títulos explícitos: "Que pasaría si Fernando Vallejo ganara el premio Nobel» y "Mejor Vallejo que Gabo» ${ }^{16}$. En este artículo el periodista arriesgaba una rápida valoración estética de sendas obras de la que al fin y al cabo salía vencedor Fernando Vallejo:

García Márquez escribe muy bello. Demasiado. Pero, como dice una balada: hasta la belleza cansa. Y Rimbaud, un día, sentó a la belleza entre sus piernas y la sintió amarga... ¡y la injurió! Vallejo está más cerca de Rimbaud, y desde luego está más cerca de nosotros. Es por eso que lo preferimos.

Recordemos sin embargo que Fernando Vallejo ni siquiera le otorga a Gabo el don de «escribir bello». Los defectos que encontraba a su prosa en el documental de Luis Ospina ya los había adelantado en una entrevista a Radio Punto de Guatemala en agosto de 2002 retomando la acusación de plagio, injustificada en mi opinión, que Miguel Ángel Asturias había

14. Laura Durango, «Vallejo se despide de la literatura», in la prensa.com.sv, 31 de enero de 2003, consultado el 7 de febrero de 2009 en el sitio http://archive.laprensa.com.sv/20030131/ cul1.asp.

15. Juan Carlos Iragorri, "Cada día se escribe peor», in El tiempo, sección cultura, 12 de julio de 1998, consultado el 7 de febrero de 2009 en www.eltiempo.com/archivo/documento/ MAM-814084).

16. Respectivamente en $\mathrm{SoHo}, \mathrm{n}^{\circ} 46,11$ de octubre de 2003 y n $^{\circ} 56,20$ de octubre de 2004 (consultados el 01.02.2009 en los sitios www.soho.com.co/wf_InfoArticulo. aspx?IdArt=1542 y 2450). Al último artículo contestó D. Artagnan en «La puntería de Gabo», in El tiempo del 24 de octubre de 2004 (www.eltiempo.com/archivo/documento/ MAM-154198). 
dirigido a García Márquez quien hubiera copiado lo de los pescaditos de oro del coronel Aureliano Buendía de un personaje de La búsqueda del infinito de Balzac. Además Vallejo hubiera declarado en aquella oportunidad ${ }^{17}$ :

El plagio no era así, el plagio es que le robó el alma al otro, porque Balzac escribió en una prosa cocinera y Cien años de soledad está escrita en una prosa cocinera chismosa del que va a destapar la olla a ver lo que está cocinando. [...] No es una prosa inspirada, dignificada por el habla, no es un escritor que tenga un conocimiento al escribir [...] con procedimientos sintácticos, con un léxico deslumbrante.

Ya en una entrevista al escritor mexicano Juan Villoro publicada a principios del mismo año 2002 había tratado a Flaubert y Balzac de «comadres» sin mencionar a García Márquez: «Todo lo que escribieron me suena a chisme. A chisme de prosa cocinera ${ }^{18}$.»

Pero quizá más interesantes que estas disquisiciones, que por cierto ponen en juego éticas, ideologías, visiones del mundo enfrentadas sin dejar de tener aspectos anecdóticos, serían las huellas que la escritura de Gabo hubiera dejado en las autoficciones de Fernando Vallejo. De existir serían forzosamente de naturaleza alusiva, bajo la forma a lo mejor de reminiscencias o de indirectas de la misma clase que las del «Cursillo de orientación ideológica para García Márquez» o del discurso a los escritores colombianos de 1998.

Mera coincidencia, pero digna de destacarse desde el punto de vista sociológico, me parece el hecho de que las respectivas abuelas maternas contaran a los niños Gabito y Fernando historias «de brujas, terroríficas, siniestras» ${ }^{19}$. Se trataría más bien de un dato cultural común pese a las diferencias entre la sociedad costeña y la antioqueña. ¿Será también casual el encuentro discursivo de ambos escritores al describir los efectos cromáticos de la división entre conservadores y liberales? Vallejo, a pesar de ser de familia conservadora por el padre, quien fue director del periódico El Poder, senador de esta tendencia política y ministro de Laureano Gómez, no tiene palabras suficientemente duras o sarcásticas para condenar la mortal oposición:

Se nace conservador o liberal como se nace hombre o mujer, y así se muere. Es cuestión de cromosomas. En los pueblos conservadores

17. Empleo el modo irreal por desconfiar del texto, plagado de errores, de la noticia transmitido por la agencia AFP, reproducido en El tiempo, 20 de agosto de 2002 y consultado el 25/01/2009 en el sitio www.eltiempo.com/archivo/documento/MAM-1324354.

18. Juan Villoro, "Fernando Vallejo: "De lo único que me considero artista es de la supervivencia"”, in Babelia (suplemento cultural de El País), 5 de enero de 2002, pp. 2-3.

19. Fernando Vallejo, Los días azules, in El río del tiempo, ed. cit., p. 30. 
las puertas y las ventanas van pintadas de azul; en los liberales de rojo. El que las pinte de verde, vaya por caso, está en el limbo de la política, doblemente jodido: enemigo de los unos y de los otros. De los pueblos y zonas conservadoras se destierra a los liberales, y viceversa: por estética; porque sus casas con su color chillón rompen la discreción del paisaje. Cromofobia ${ }^{20}$.

De sobra conocido es el episodio de la llegada a Macondo del corregidor conservador don Apolinar Moscote cuya «primera disposición fue ordenar que todas las casas se pintaran de azul para celebrar el aniversario de la independencia nacional ${ }^{21}$. Contra lo que José Arcadio Buendía, el fundador de Macondo todavía políticamente inocente, o sea "en el limbo de la política», se rebela increpando al corregidor: «[...] si viene a implantar el desorden obligando a la gente que pinte su casa de azul, puede agarrar sus corotos y largarse por donde vino. Porque mi casa ha de ser blanca como una paloma ${ }^{22}$.»

Más transparente es la alusión abiertamente despreciativa a la anciana Fermina Daza de El amor en los tiempos del cólera, novela publicada en diciembre de 1985. En Los caminos a Roma (1988), Vallejo recuerda que su abuela Raquel «ha viajado en esos barcos de vapor con rueda que van por entre caimanes echando humo por el Magdalena y que tan famosos se hicieron a fines del siglo XX, pero ella es una maravilla, un personaje de carne y hueso, gorda, de ojos verdes hermosos, no un mamarracho de ficción» ${ }^{23}$.

En la categoría de las oposiciones hipotéticas está la aversión del narrador de La Virgen de los sicarios (1994) por los vallenatos («[...] llevaba el taxista

20. Id., pp. 39-40.

21. Cien años de soledad, ed. cit., p. 150.

22. Íd., pp. 151-152.

23. Los caminos a Roma, in El río del tiempo, p. 388. Consabido es que los dos escritores quisieron estudiar cine en Roma. El neorrealismo italiano de la postguerra es motivo de otro desencuentro estético entre Gabo y Vallejo. Aquél no dejó de expresar su admiración por Cesare Zavattini (véase por ejemplo «La penumbra del escritor de cine» [artículo publicado el 17 de noviembre de 1982], en Gabriel García Márquez, Notas de prensa 1980-1984, Madrid, Mondadori, 1991, p. 339), mientras que éste proclama: «Años llevo repitiéndolo: el neorrealismo es una estafa. Eso de querer meter la realidad cotidiana en la sala oscura ¡a quién se le ocurre! si la vida es gris y el cine luminoso.» (Los caminos a Roma, p. 407). Sin embargo no creo que en la expresión de Vallejo haya un ataque deliberado al gusto cinematográfico de García Márquez. También pienso que el olor «a espuma de coliflores hervidas» del cuarto del hotel parisino de Gabriel (Cien años de soledad, ed. cit., p. 537) y el «a col hervida y cebolla» de la pensión romana de la signora Emma de Los caminos a Roma (El río del tiempo, p. 420) es mera coincidencia. 
el radio prendido tocando vallenatos, que son una carraca con raspa y que no soporta mi delicado oído ${ }^{24}$ ). y los ditirambos que dirige García Márquez a este género folklórico de la costa atlántica colombiana y a sus compositores e intérpretes como el Rafael Escalona de las crónicas periodísticas más tempranas y Francisco el Hombre de Cien años de soledad ${ }^{25}$. La hipótesis se precisa algo en la definición de La Rambla paralela (2002): «los vallenatos, esa carraca infecta que se oye en Colombia en la costa ${ }^{26} \%$.

A la misma categoría de las posibles reminiscencias de la peste del insomnio y del olvido de Cien años de soledad en La Rambla paralela es el siguiente caso. Para no olvidar los nombres y usos de las cosas, los habitantes de Macondo les pegan unos papelitos hasta cuando llegan a perder el secreto de la lectura ${ }^{27}$. El viejo insomne de La Rambla paralela quiere abrir la caja fuerte de su cuarto de hotel:

El problema iba a ser abrirla. ¿Por qué letra empezaba la clave que él mismo escogió? ¿Por «a», por «b», por «c»? A él desde hacía mucho no le fallaba la memoria: le fallaba la mnemotecnia. Hombre precavido, había apuntado la clave en un papelito. Pero, ¿̇ónde había metido el papelito? Acudió entonces al gerente del hotel y el gerente del hotel al cerrajero. Abrieron la caja fuerte a la brava y adentro, en el único lugar del mundo donde no debía estar, ahí estaba, junto al dinero, inocente, el papelito ${ }^{28}$.

De tomar más cuerpo la hipótesis de la reminiscencia, nos las habríamos con un desvío irónico de uno de los episodios más famosos de la novela de culto de Gabo con una aporía («no le fallaba la memoria: le fallaba la mnemotecnia») que se mofa del tan celebrado pasaje. Por otra parte, la tela de fondo de La Rambla paralela es una Feria del Libro de Barcelona donde tiene que hablar el viejo en tanto escritor representativo de Colombia, país invitado aquel año. El texto no menciona para nada a García Márquez ni tampoco, es verdad, a otros escritores colombianos sino como colectividad anónima ${ }^{29}$.

24. Fernando Vallejo, La Virgen de los sicarios, México, Suma de letras, «Punto de lectura», 2005 , p. 67.

25. Gabriel García Márquez, Obra periodistica. Vol. 1 Textos costeños, recopilación y prólogo de Jacques Gilard, Barcelona, Bruguera, 1981, pp. 225-226, 614-615, 632-634.

26. Fernando Vallejo, La Rambla paralela, Madrid, Alfaguara, 2002, p. 167.

27. Cien años de soledad, ed. cit., pp. 136-141.

28. La Rambla paralela, p. 157.

29. En la realidad, se trata de la Feria del Libro de Barcelona del 2 al 13 de julio de 1998 donde estuvieron presentes y hablaron en un quiosco instalado por la librería Biblos de Bogotá además de Fernando Vallejo, Antonio Caballero, Alfredo Molano, Héctor Abad 
El ninguneo fue, pues, un proceso recurrente de descalificación de Gabriel García Márquez usado por Fernando Vallejo. Puede afirmarse que la recíproca ha funcionado de la forma más radical posible. Que yo sepa y sepan los biógrafos de Gabo consultados por mí, éste no menciona, ni alude, ni cita siquiera indirectamente a su contrincante ${ }^{30}$. A las repetidas y constantes agresiones verbales de Vallejo desde, digamos, 1988 con la alusión despectiva de Los caminos a Roma a El amor en los tiempos del cólera, García Márquez ha contestado por el silencio.

La historia literaria de los países hispánicos -y no sólo la de ellos ${ }^{31}$ abunda en acérrimas polémicas entre escritores de personalidad fuerte y hasta cascarrabias: pensemos en las famosas del Siglo de Oro de cuyos antagonistas no quiero acordarme. Y la historia literaria se acuerda de sus nombres y obras porque eran genios y figuras. ¿Dudaría algún lector de que fuera diferente la conclusión de quien ha dedicado buena parte de sus vigilias al estudio de la prosa de quien encabezó una novela justamente celebrada por las palabras que todos recordamos: «Muchos ańos después, frente al pelotón de fusilamiento, el coronel Aureliano Buendía había de recordar aquella tarde remota en que su padre lo llevó a conocer el hielo.»?32

Faciolince, Álvaro Mutis, Germán Espinosa, R.H. Moreno Durán, Álvaro Pineda Botero, Óscar Collazos, Conrado Zuloaga y un largo etc. (véase Juan Carlos Iragorri, «Dardos al oficio literario", El tiempo, sección Cultura, 13 de julio de 1998, (consultado el 25/01/2009 en el sitio www.eltiempo.com/archivo/documento/MAM-768376).

30. Gerald Martin me escribe en un correo electrónico del 25 de enero de 2009: «Mi impresión es que Gabo no ha mencionado a Vallejo en la prensa y la verdad es que Vallejo ha sido especialmente agresivo precisamente en la época en que Gabo ha estado enfermo y, por consiguiente, en que ha dicho menos que nunca.» Con fecha del 6 de febrero de 2009, Dasso Saldívar confirma: «Nunca supe que Gabo le hubiera contestado a Vallejo. Sabes que Gabo no contesta nunca a sus críticos, menos cuando éstos se expresan con insultos y groserías, como es el caso de Vallejo.» La respuesta de Plinio Mendoza, consultado por Dasso (mensaje electrónico del 5 de febrero de 2009), fue: «Gabo nunca le ha contestado a Vallejo. Simplemente lo ignora. "

31. Así para la literatura francesa, véase Anne Broquel y Etienne Kern, Histoire des haines d'écrivains. De Chateaubriand à Proust, París, Flammarion, 2009.

32. A la hora de corregir las pruebas de este trabajo, leo la excelente contribución de Fernando Díaz Ruiz, "Tras las huellas de Macondo en la Sabaneta de Fernando Vallejo», dans Camacho Delgado, José Manuel, y Díaz Ruiz, Fernando, Gabriel García Márquez, la modernidad de un clásico, Madrid, Verbum, 2009, pp. 42-62. En lo fundamental esta lectura no entrańa una revisión de las líneas anteriores. 